\title{
Molten metal's reaction force measurement for pressure estimation and control system construction in press casting
}

\author{
Ryosuke Tasaki, Kazuhiko Terashima \\ Department of Mechanical Engineering, Toyohashi University of Technology, Japan
}

\section{ABSTRACT}

This paper presents a measurement system for molten metal's reaction force and estimation of liquid pressure during pressing to control the iron product quality. We have developed a new type of casting process. In the process, molten metal is quickly filled into casting molds by high-speed pressing. Casting defects such as physical metal penetration is often caused by excess pressure. Hence, we have constructed a pressure control system using a mathematical model-based off-line simulation to derive the ideal feedforward control input of pressing. However, it is difficult to accurately control the pressure in cases of varying conditions such as liquid volume and temperature changes. Also, pressure measurements by using contact-type sensors directly is impossible for molten metal, because of the high temperature of the liquid, over $1400{ }^{\circ} \mathrm{C}$. So, we have proposed a new pressure estimation method with force measurement data processing. Here, the exact reaction force from the molten metal must be accurately observed by a force sensor set between the upper mold and its elevating device. The viscosity coefficient can also be calculated on a real-time basis. The proposed force measurement system will realize an improved casting quality due to the effective feed-back control system.

Section: RESEARCH PAPER

Keywords: force measurement; soft-sensing; model-based estimation; casting process

Citation: Ryosuke Tasaki, Kazuhiko Terashima, Molten metal's reaction force measurement for pressure estimation and control system construction in press casting, Acta IMEKO, vol. 6, no. 2, article 9, July 2017, identifier: IMEKO-ACTA-06 (2017)-02-09

Section Editor: Min-Seok Kim, Research Institute of Standards and Science, Korea

Received June 30, 2017; In final form June 30, 2017; Published July 2017

Copyright: (C) 2017 IMEKO. This is an open-access article distributed under the terms of the Creative Commons Attribution 3.0 License, which permits unrestricted use, distribution, and reproduction in any medium, provided the original author and source are credited

Corresponding author: Ryosuke Tasaki, e-mail: tasaki@me.tut.ac.jp

\section{INTRODUCTION}

A new casting method called sand mold press casting, has been developed by our group over recent years. In this casting process, the ladle first pours the molten metal into a lower (drag) mold. After the pouring, an upper (cope) mold is lowered to moderately press the molten metal into the cavity. This process has enabled us to enhance the production yield rate from $70 \%$ of typical gravity casting to over $90 \%$, because the sprue cup and the runner are not needed for the suggested casting plan [1]. In the casting process, the molten metal can precisely and quickly be poured into the lower mold. Liquid weight control during pouring with the tilting ladle has been proposed in very interesting recent studies [2], [3]. However, in the pressing part of this casting process, casting defects are often caused by high pressure inside the mold related to pressing velocity. A major application example of the casting method is metal impeller production, shown in Figure 1. High velocity pressing of molten metal induces product defects as a rough surface at the bottom of the upper mold. This type of casting defect, in which molten metal soaks through sand particles of the greensand mold and then solidifies, is called physical metal penetration. The penetration is most likely caused by the high pressure, and it requires an extra process of surface finishing. Thus, high quality stable casting must be enabled by excess pressure suppression in the pressing process. To maintain a shorter cycle time in production, a pressing control system, considering the liquid pressure behaviour inside the mold, is highly demanded. Pressure control techniques have

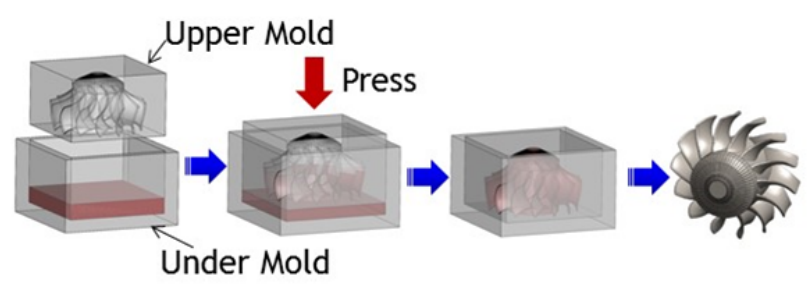

Figure 1. Press casting process and its iron product. 
been proposed for different casting methods, especially the injection molding process with metallic mold [4], [5]. The pressure control problem has been successfully resolved by mathematical modelling of liquid behavior and computing a 3D simulation analysis [6], [7]. Furthermore, a feedback pressure control based on PID gain selection has been proposed for the filling process. Although the pressure in the mold must be detected in order to control the process adequately using feedback control, it is difficult to measure the fluid pressure directly, because the high temperature of the molten metal over $1400{ }^{\circ} \mathrm{C}$ precludes the use of a pressure sensor. Thus, in our previous papers [8], [9], the pressure during pressing at a lower pressing velocity was estimated by using a simple model of the molten metal's pressure based on the analysis results of the Computational Fluid Dynamics (CFD) software. A new sequential pressing control, namely a feedforward method using a novel simplified pressure model, has been reported by the authors [10], [11]. It has been shown that this method is very effective for adjusting the pressure in the mold.

As the main work in this paper, we have undertaken several pressing experiments using viscous water to validate a force measurement algorithm for liquid pressure estimation inside the mold, and to confirm the modified pressure control model and a feed-forward control method during pressing. These results indicate that measuring the pressure during pressing is desired to achieve quality casting under a variety of conditions as the poured liquid volume and temperature changes. Therefore, we have proposed an indirect pressure measurement for the estimation method using the information about the reaction force from the molten metal during pressing. In the final section, the proposed pressure estimation method is applied to a water pressing experiment using an acrylic mold, shaped as a simple injection type. The effectiveness for the actual flow situation, which means viscous flow depending on varying molten metal temperature, is discussed

\section{PRESSING PROCESS IN PRESS CASTING}

\subsection{Servo drive pressing machine}

The filling molds consist of greensand in the actual casting production. The convex part of the upper mold has several passages called the overflow area. Molten metal that exceeds the product volume flows into the overflow areas during pressing. These areas are the only parts of the casting plan that provide the effect of liquid static pressure. The overflow part is designed as long and narrow channels. When fluid flows into such an area, high pressurization causes casting defects.

Therefore, it is important to control the pressing velocity in order to suppress the rapid increase in pressure that occurs in high-speed pressing. The upper mold moves up and down by a lifting press cylinder driven by a servomotor, as shown in Figure 2. The position of the upper mold can be continuously measured by an encoder mounted on the servo cylinder that controls the molten metal pressure by using the controlled velocity input. The force sensor for measuring the molten metal's reaction force is mounted between the bottom part of the servo cylinder and the top of the upper metal molding box covering the greensand.

\subsection{Metal production experiments}

Casting production tests by press casting have been performed using the previously proposed pressing control. Figure 3 shows an overview of the cast product pressed by

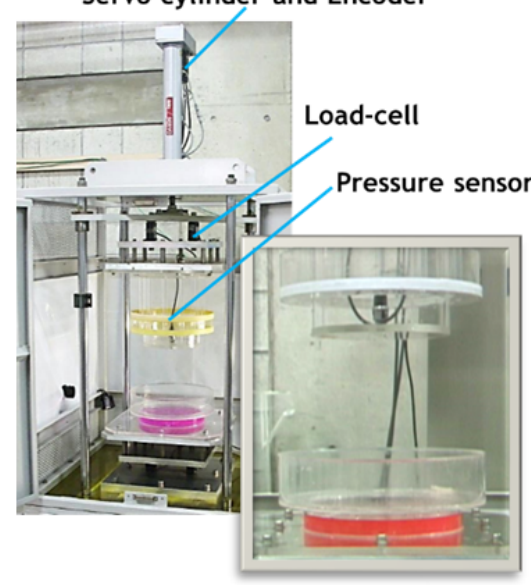

Figure 2. Press casting equipment.

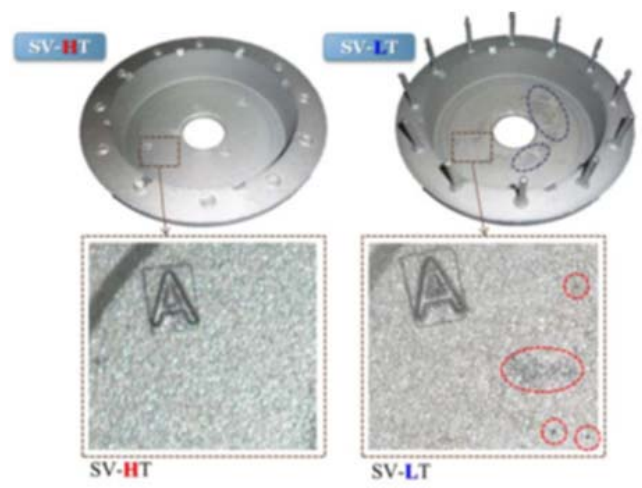

Figure 3. Casting products in case of different temperature.

sequentially switched velocity pattern SV. These two products are cast under the experimental condition of higher temperature HT $\left(1400{ }^{\circ} \mathrm{C}\right)$ on the left side in Figure 3, and the right-hand side shows the results tested with lower temperature LT (1350 $\left.{ }^{\circ} \mathrm{C}\right)$. From these photographs, a better product of SV-HT is clearly verified, because the switch velocity is designed for the higher temperature condition $\left(1400^{\circ} \mathrm{C}\right)$.

On the other hand, the case of SV-LT has a tiny penetration part, because a higher pressure is generated with higher viscosity related to the lower temperature. This comparative validation result of the different temperatures indicates that for quality casting an adjustable pressing control depending on the molten metal's temperature drop during pressing is desired. It can be well performed by using both of model based designs of pressing velocity and the pressure control with a known parameter related to liquid viscosity.

\section{REACTION FORCE MEASUREMENT FOR PRESSURE ESTIMATION}

\subsection{Reaction force measurement for pressure}

In actual production, the poured volume and metal temperature are susceptible as a repeating error for each pouring. The optimal higher pressing process is done by sensing the variable volume error and temperature change from the measured liquid pressure inside the mold. Therefore, a real- 
time pressure estimation algorithm and its confirmative experiments are required for the construction of a new control system for press casting.

The installation of a contact-type pressure sensor to measure the molten metal pressure is quite difficult due to the high liquid temperature of the molten metal. Therefore, an indirect sensor by reaction force is implemented above the upper mold. By using the reaction force from the load-cell, a pressure estimation of the liquid inside the mold is validated. Water pressing experiments have been carried out to directly measure the pressure by this contact-type sensor, to observe the flow state and to estimate the pressure by the load-cell. An illustration of the experimental equipment and sensing/control system is shown in Figure 4.

\subsection{Pressure estimation considering frictional resistance cancellation}

Pressing motion causes frictional resistance between the upper and lower molds as shown in Figure 4. In this section, we propose a pressure estimation method using the reaction force measurement by the load cell. To remove the effect of friction as a disturbance for an accurate pressure estimation, an equation of friction force during pressing is derived. The measurable total force $F[\mathrm{~N}]$ including the effects of mold friction, inertia of the upper mold and gravity is simply derived, and then the pressure of the base area $P[\mathrm{~Pa}]$ is given by (1),

$P=(F-m g-m \ddot{z}-\mu(\dot{z}) L z) / A$

where $m[\mathrm{~kg}]$ is the mass of the upper mold, $g\left[\mathrm{~m} / \mathrm{s}^{2}\right]$ the gravity force, $z[\mathrm{~m}]$ the upper mold position, $\mu[-]$ the wall frictional coefficient, $L[\mathrm{~m}]$ the girth of the frictional part, and $A\left[\mathrm{~m}^{2}\right]$ is the area of the upper mold base. Here $\mu$ strongly depends on the pressing velocity, and also switches between both kinetic and static frictions. In (2), $\mu_{d}$ and $\mu_{s}$ are coefficients of the kinetic and static frictions respectively, $\dot{z}[\mathrm{~m} / \mathrm{s}]$ is the pressing velocity related to the frictional force.

$\mu(\dot{z})= \begin{cases}\mu_{d} & \left(|\dot{z}|>\dot{z}_{\text {lim }}\right) \\ \mu_{s}-\frac{\mu_{s}-\mu_{d}}{\dot{z}_{\text {lim }}}|\dot{z}| & \text { (otherwise) }\end{cases}$

To validate (1) and (2), water pressing experiments have been performed. A cylindrically shaped injection type mold is selected, with a diameter of $0.10 \mathrm{~m}$ at the bottom side and a smaller diameter of $0.02 \mathrm{~m}$ at the upper side. Water inside the mold flows upward during pressing. The velocity reference input and the pressure behavior are shown in Figure 5. For each pressing the liquid viscosity is changed, as experimental condition for the pressure estimation. As shown in Figure 5, the

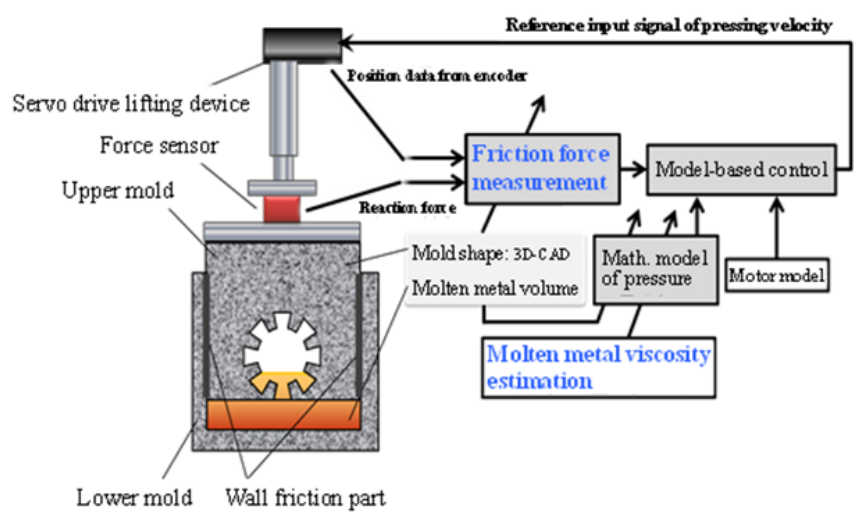

Figure 4. Block diagram of pressing control system.

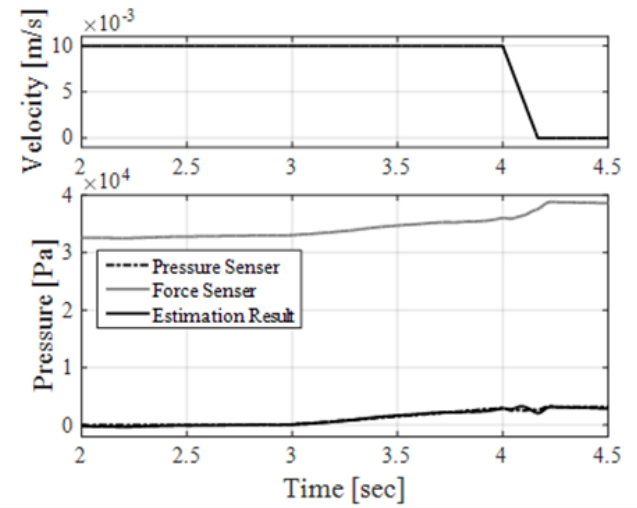

(a) $\lambda=0.001[\mathrm{cP}]$

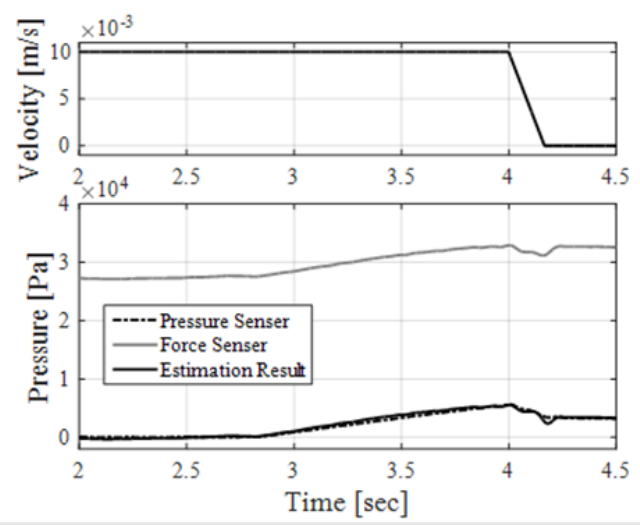

(b) $\lambda=0.500[\mathrm{cP}]$
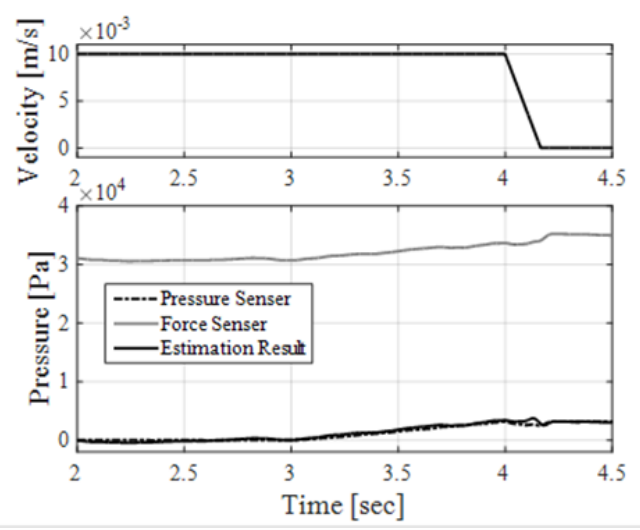

(c) $\lambda=1.000[\mathrm{cP}]$

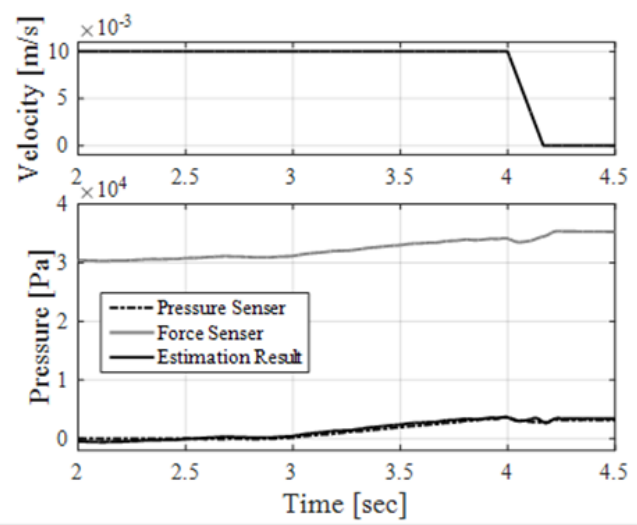

(d) $\lambda=5.000[\mathrm{cP}]$

Figure 5. Pressure estimation results for different viscous liquid. 
viscosity is adjusted to four values of $\lambda$ : (a) 0.001 , (b) 0.500 , (c) 1.000 and (d) 5.000 by $\mathrm{CMC}$ (carboxymethylcellulose)-contained water.

Dashed, solid gray and solid black lines mean the actual pressure measured by the contact-type pressure sensor (AP-10S, KEYENCE Corp.), the force measurement data by the load cell (TCLZ-500NS001, Tokyo Sokki Kenkyujo Co., Ltd.) and the estimated pressure by (1) and (2), respectively. These results make clear that the actual measured and the estimated pressure behaviors are successfully matched for all values of the liquid viscosity.

\subsection{Estimation of unmeasurable liquid viscosity}

The CFD based on the exact model such as the NavierStokes equation is very effective for offline analysis of fluid behavior and is useful for predicting the behavior and optimization of a casting plan [7], [8]. However, this is not sufficient for the design of a pressing control system, because the complex and exact model calculations take too much time. Therefore, a construction of a mathematical pressure model is desired in order to realize an efficient pressing casting control system by estimating the liquid property such as the viscosity depending on varying metal temperature and volume.

The mathematical model construction can be considered from the viewpoint of the conservation of energy in the continuous streamline from the bottom to the surface of the liquid. The pressure model construction is considered for only unstationary vertical flow without air entrainment. Figure 6 shows the rising flow of the molten metal. The unstationary Bernoulli theorem for incompressible fluids, and considering the bottom surface of the upper mold $(e h(t)=0)$ and the liquid surface $(e h(t))$, gives us the following pressure model equation:

$$
P_{B}=\rho \frac{A_{M}^{2}\left(e_{h}\right)}{A_{S}^{2}\left(e_{h}\right)}\left(\ddot{z} z+\left(\frac{1}{2}+\lambda(T) \frac{L\left(e_{h}\right)}{D\left(e_{h}\right)}\right) \dot{z}^{2}\right)+\rho g f\left(V_{p}, z\right),
$$

where $\rho\left[\mathrm{kg} / \mathrm{m}^{3}\right]$ is the fluid density and $g\left[\mathrm{~m} / \mathrm{s}^{2}\right]$ the acceleration of gravity. The fluid surface position $e_{b}[\mathrm{~m}]$ and its velocity $\dot{e_{h}}[\mathrm{~m} / \mathrm{s}]$ at the free surface $A_{S}\left[\mathrm{~m}^{2}\right]$ relate to the mold cross-sectional area $A_{M}\left[\mathrm{~m}^{2}\right]$ and the pressing velocity $\dot{z}$. Furthermore, $\lambda$ means the wall frictional coefficient depending on the liquid temperature $T[\mathrm{~K}]$ on the upward flow. $L[\mathrm{~m}]$ and $D[\mathrm{~m}]$ are the vertical flow length and the diameter, respectively. To properly control the pressure behavior inside the casting mold, the unknown temperature depending on parameter $\lambda$ could be identified by the mathematical model (3) as given above and the estimated data mentioned in the previous section. (See [11] for more information about the mathematical model construction).

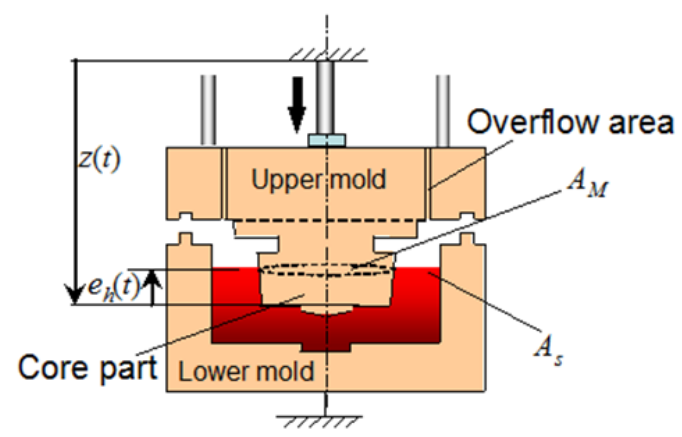

Figure 6. Illustration of filling flow state shown in cross-sectional view.
To confirm the proposed viscosity identification by using the mathematical pressure model, several experiments using a simple injection type mold have been carried out. In the experimental results shown in Figure 7, the estimated pressure behavior of solid black lines are reshaped with the identified parameter $\lambda$ from the reference output $(\lambda=0)$ related to mathematical model. Here, the trapezoidal pressing velocity input is set to the same reference in Figure 5. Fitting the model based time behavior to the estimated pressure by force sensing, the unknown parameter $\lambda$ has been uniquely derived for each different viscous liquid. The relationship between viscosity and $\lambda$ is almost linear as shown in Figure 8.

\section{MODEL PREDICTIVE CONTROL APPROACH}

The pressure control must satisfy the pressure constraint condition for high-quality sand mold casting. The MPC method first predicts the future output, calculates the optimum input for keeping the constraint, and then realizes a good performance of the real output. In our MPC approach, we have built a predictive model control system with high speed calculation, therefore it is effective for real-time feedback control. Equation (4) is the response of the system. The response $\tau$ should be equal to the reference pressure trajectory $\tau_{r}$,

$\tau=y_{f}+S u$.

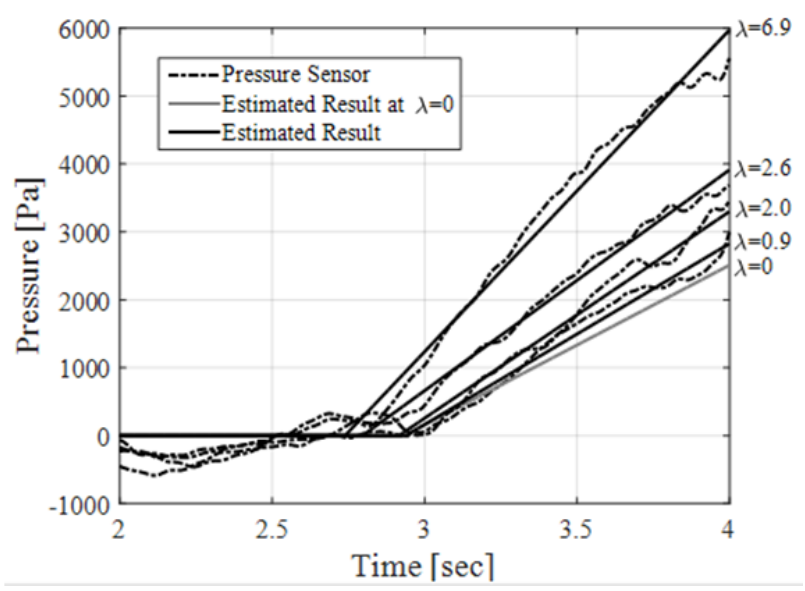

Figure 7. Pressure estimation with identified $\lambda$.

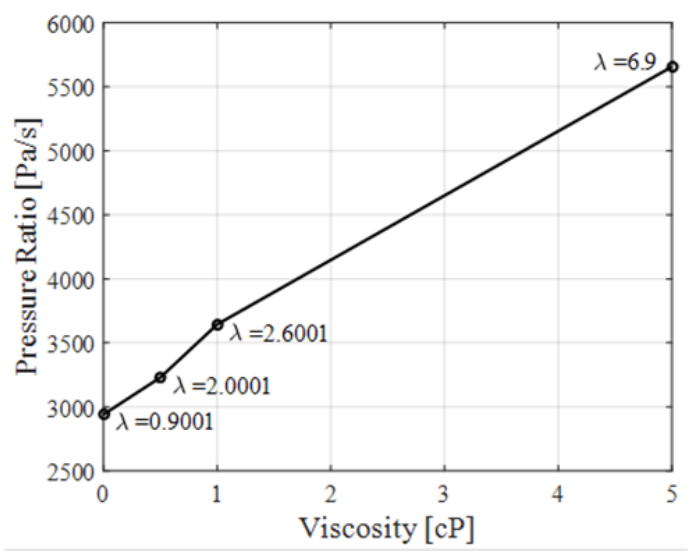

Figure 8 . Identification parameter of $\lambda$. 
The optimal control input $u$ is given by

$u=\left(S^{T} S\right)^{-1} S^{T}\left(\tau_{r}-y_{f}\right)$,

where $y_{f}$ is the free output response on the time in the future and $S$ the unit step response matrix. The MPC simulation result is shown in Figure 9. This simulation result confirms that the MPC is very effective for the liquid pressure control during pressing in the press casting process.

\section{CONCLUSIONS}

For a practical application of the casting quality control system in the press casting process, we have proposed an implementation approach of force measurement, pressure estimation and parameter identification for molten metal during dynamic filling. It is made clear that the molten metal pressure inside the casting mold is accurately estimated by the reaction force from a force sensor mounted between the upper mold and its elevating device. From the estimated pressure behavior, the actual pressure behavior can be calculated with the identified liquid viscosity using the constructed mathematical pressure model. Next, the filling behavior of the upward flow liquid can also simultaneously be observed on a real-time basis. In the case of varying casting conditions such as mold shape, molten metal properties, volume and temperature as seen in practical cases, our proposed real-time estimation method in

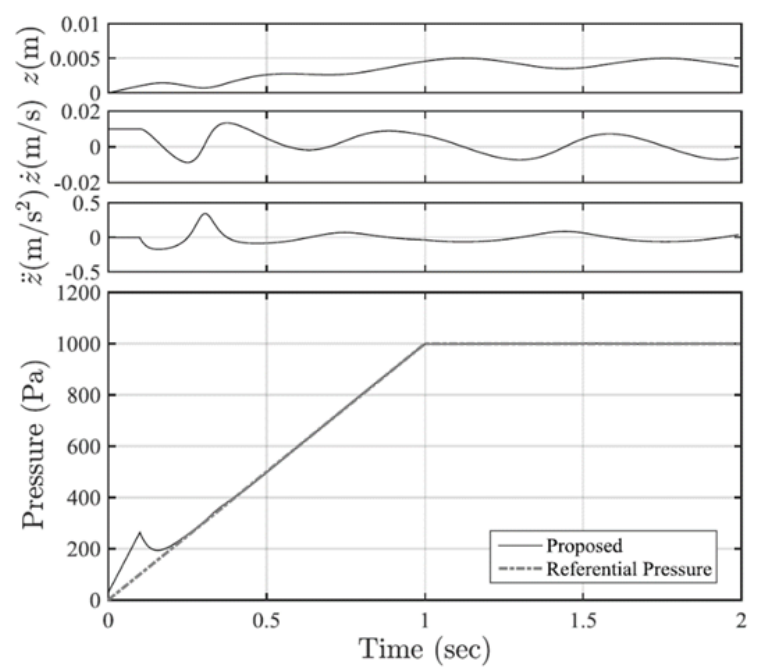

Figure 9. Pressure behaviour on MPC simulation. this paper can be effectively integrated with a next-generation supervisory process control system for metal manufacturing. In the near future, optimum quality control experiments using molten metal, based on the model predictive control algorithm, will be demonstrated.

\section{REFERENCES}

[1] K. Terashima, Y. Noda, K. Kaneto, K. Ota, K. Hashimoto, J. Iwasaki, Y. Hagata, M. Suzuki and Y. Suzuki, "Novel Creation and Control of SandMold Press Casting "Post-Filled Formed Casting Process", Foundry Trade Journal International (The Journal of The Institute of Cast Metals Engineers), No. 183 (3670), (2009) pp. 314-318.

[2] Y. Noda and K.Terashima, "Modeling and feedforward flow rate control of automatic pouring system with real ladle", Journal of Robotics and Mechatronics, Vol. 19 (2), (2007) pp. 205 - 211.

[3] Y. Noda, K. Yamamoto and K. Terashima, "Pouring Control with Prediction of Filling Weight in Tilting ladle-type Automatic Pouring System", International Journal of Cast Metals Research, Science and Engineering of Cast Metals, Solidification and Casting Processes, AFC-10 Special Issue, Vol. 21(1-4), (2008) pp. 287-292.

[4] Hu, J, Vogel. J. H, "Dynamic modeling and control of packing pressure in injection molding", Int. Journal of Engineering Materials and Technology, vol. 116, No.2, (1994) pp. 244-249.

[5] Mickowski J. R, Teufert, C. E, "The control of impact pressure in the high pressure die casting process", Trans 17th Int. Die Cast Congress and Exposition, (1993) pp. 349-354.

[6] H. Devaux, "Refining of melts by filtration. a water model study", In Proc. of 53rd International Foundry Congress, Prague, Czech, (1986) pp.107-115.

[7] C. Galaup, U and H. Luehr, "3d visualization of foundry molds filling”, In Proc. of 53rd International Foundry Congress, Prague, Czech, (1986) pp.117-127.

[8] I. Ohnaka, "Development of the innovative foundry simulation technology", In Journal of the Materials Process Technology, "SOKEIZAI", vol.45, No.9, (2004) pp. 37-44.

[9] K. Terashima, R. Tasaki, Y. Noda, K. Hashimoto, J. Iwasaki, T. Atsumi, "Optimum Pressure Control of Molten Metals for Casting Production Using a Novel Greensand Mold Press Casting Method", Key Engineering Materials, Vol. 457, (2011) pp. 453-458.

[10] R. Tasaki, Y. Noda, K. Terashima, K. Hashimoto, "Sequence Control of Pressing Velocity for Pressure in Press Casting Process Using Greensand Mold", Journal of Cast Metal Research, Vol. 21, No. 1-3, (2008) pp. 369-374.

[11] R. Tasaki, Y. Noda, K. Hashimoto and K. Terashima, "Modelling and Control of Pressurized Molten Metal in Press Casting", Journal of Mechanics Engineering and Automation (JMEA), Vol. 2, No. 2, (2012) pp.77-84. 